\title{
Innovación aplicada a la producción de contenidos transmedia en publicidad
}

\author{
Luis Piquer Trujillo \\ Director general de Publips-Serviceplan \\ y productor ejecutivo del film Paella Today!
}

\section{Referencia de este artículo}

Piquer Trujillo, Luis (2017). Innovación aplicada a la producción de contenidos transmedia en publicidad. En: adComunica. Revista Científica de Estrategias, Tendencias e Innovación en Comunicación, $\mathrm{n}^{0} 14$. Castellón: Asociación para el Desarrollo de la Comunicación adComunica y Universitat Jaume I, 255-257. DOI: http://dx.doi.org/10.6035/2174-0992.2017.14.14

La publicidad va muy deprisa. Tanto que, a veces, ciertas marcas no saben cómo adaptarse a las nuevas demandas de contenidos por parte del público. La publicidad, per se, la que no engancha ni despierta ningún tipo de emoción o curiosidad en el usuario ha perdido interés y, lo que es peor, eficacia.

Numerosos estudios apuntan a que los millennials consumen la publicidad como un contenido más. El branded content digital ya no es algo intrusivo. Simplemente, si les gusta, lo compartirán. Y la viralización es lo mejor que le puede ocurrir a una marca. Pero para ello, debe haber una estrategia de marca y una producción publicitaria disruptiva e impecable.

Mucho se habla de estos días de narrativa transmedia, de la cocreación y feedback en el usuario, en el destinatario final; de que la suma del todo ha de aportar mucho más que la suma de las partes. Y es así, claro, debe ser así. Pero a mí me gustaría hablar desde el punto de vista de la producción audiovisual y cinematográfica con varios ejemplos que hemos liderado desde la agencia 
Publips-Serviceplan como el proyecto audiovisual de Julio Medem, "El pelotari y la Fallera" para Amstel o como la película "Paella Today!” de la cual soy productor ejecutivo.

En el caso de "El Pelotari y la Fallera" ha sido el primer corto en estrenarse en televisión y cuya premiere, en los cines Callao, fue retransmitida íntegramente por Atresmedia y se pudo seguir por los canales sociales de la marca. Además, es la primera vez que las etiquetas de unos botellines de cerveza narran la historia de una película de la mano de dos reconocidos ilustradores: la valenciana Carla Fuentes y el guipozcoanoa Iban Barrenetxea.

Otro ejemplo de innovación aplicado a la producción audiovisual publicitaria ha sido la última campaña transmedia que realizamos para Viceroy en la que, en tiempo real, y a través de las redes sociales los espectadores pudieron elegir el final de un espot.

Producir contenidos transmedia de este tipo, desde la innovación, puede resultar beneficioso para las marcas (con ROE, retorno emocional de sus audiencias gracias a los elevados índices de engagement) pero también para las instituciones que las abanderan. Además, pueden ser una fantástica vía de financiación de entes televisivos públicos y privados. En concreto, en la Comunidad Valenciana tenemos una gran oportunidad con la televisión a.punt que está a punto de echar a volar, para crear una plataforma de contenidos más allá de una mera televisión analógica. Muchos de estos pueden ser patrocinados por las marcas y tener visibilidad dentro y fuera de la pantalla. Bien a través de, por supuesto product placement, en eventos, merchandising, brandutilities o en redes sociales... Un complemento, desde la vertiente privada más allá de los bloques de anunciantes convencionales, que se sumaría a la financiación pública, de continuarse aplicando la fórmula mixta de financiación (como hacen el resto de televisiones autonómicas en España).

En este sentido, el último caso de éxito en el que hemos trabajado es "Paella Today!”. Una buena muestra de contenido netamente transmedia. Un ejemplo de innovación aplicado a la producción publicitaria redondo. "Paella Today!” no es solo un largo de ficción que pretende poner en valor la Comunidad Valenciana, injustamente tratada durante los últimos años, es además, un contenido transmedia en el que conviven el cine, la música, las redes sociales y la literatura.

"Paella Today!" comenzó cuando un ex compañero de la agencia, César Sabater, nos trajo un primer guión de la película. Enseguida vimos grandes posibilidades en ese guión, no sólo como proyecto cinematográfico y como una historia que reflejaba nuestra zona de origen, el Mediterráneo español, con un tono más fresco, joven y mucho humor. Vimos algo muy interesante, un contendido para relatar una historia estupenda, con unos mensajes y valores con los que nos identificábamos y un proyecto que podría ser mucho más que una película. Y así comenzamos a trabajar para poder hacerla crecer 
A partir de ahí, nació el proyecto "Paella Today!", una estrategia que parte de una película de entretenimiento pero, como decía, es también una plataforma de creación de otros productos y contenidos con múltiples objetivos: cinematográficos, culturales, promocionales, etc.

Ante todo, la acción troncal es la película de humor que muestra valores positivos como el amor en todas sus facetas, la libertad, la solidaridad, la amistad, la empatía y la necesidad de poner un poco más de humor en nuestra vida, todo a través de sus diferentes personajes y otros valores del Mediterráneo español, más alejados de los asociados a la imagen de los últimos años de malas noticias y corrupción política.

"Paella Today!" también pone en relieve la irritación constante de una sociedad por temas a veces más triviales que se refleja, por ejemplo, en la polémica de la verdadera receta de la paella y todo lo que ello suscita. Eso supone un espejo de la polarización de la sociedad y la irritación innecesaria que también se ve en campos como la política, la televisión y otros temas en general.

A partir del primer guión, llegamos a hacer diecisiete versiones, para terminar en la historia que queríamos contar y así empezaron a surgir otros productos e ideas. Una novela, videoclips con músicos de la zona, trailers brandeados de las marcas que participan, merchandising, productos relacionados con la paella (que es un icono internacional), como un documental del origen de la paella, hasta contenidos turísticos de las localizaciones de la película...

Es un proyecto cinematográfico que pilota la agencia pero no como la publicidad de siempre. Son contenidos en muchos formatos con diferentes objetivos, aunque la película es lo primero.

Una agencia también puede hacer cine, sobre todo, si ya estamos haciendo todo tipo de formatos y contenidos nuevos, fuera de los convencionales de siempre. Nosotros hace diez años ya hicimos un corto "Lima Splash" y hoy son muchas las agencias que se han sumado a esta tendencia.

También es un proyecto un tanto romántico, con un tinte menos publicitario para contar cosas que nos interesan. Después, se sumaron las marcas que también han querido apoyarlo al ver todas las posibilidades que ofrece.

En definitiva, "Paella Today!" es una respuesta a la imagen creada durante un tiempo de un territorio, la Comunidad Valenciana, en el imaginario colectivo. Además de una película, es un contenido sobre el Mediterráneo y su gente y un bálsamo de humor. Con una historia con la paella como reclamo internacional de trasfondo, "Paella Today!" cuenta, además, con un gran reparto: Pablo Rivero, Olga Alamán, Pau Gregori, Albero Jo Lee, Lolita Flores, David Amor, Mamen García, Brays Efe o Pablo Carbonell, entre otros.

Un contenido transmedia líquido con infinidad de posibilidades cuyo suma resultante es mayor que la de todas sus partes. 